\title{
Obituary
}

\section{In memory of Bruce Howard Rankin (January 19, 1953-November 12, 2020)}

Murat Ergin

The untimely passing of Bruce Rankin, a retired member of Koç University's sociology program, is an incalculable loss for all those who cherished his brilliant scholarship, engaged teaching, and life filled with decency, integrity, and solicitude for the well-being of others. An Oregon native, Rankin received his $\mathrm{BSc}$ degree in economics from Portland State University, and his MA and $\mathrm{PhD}$ degrees in sociology from the University of Maryland in College Park. He was a research coordinator at the University of Chicago's Center for the Study of Urban Inequality (1993-7) and a research associate at Harvard University's Joblessness and Urban Poverty Research Program (1997-2000) before joining Koç University until his retirement in 2015.

Bruce Rankin bequeathed an extensive body of scholarship that was driven by a meticulous sociological attention to social stratification and a concern for justice in diverse domains of life including education, employment, and culture. While his concern for inequalities was the central theme of his scholarship, Rankin's sociological eye responded to the particular conditions of local struggles with incisive empirical work. Regarding the empirical focus, his work reflects two broad episodes corresponding to his time in the United States and in Turkey.

In his early years in College Park, Cambridge, and Chicago, Rankin published key articles on the effects of race on earnings, showing that income disparities in the American rural South go beyond individual and quality-of-work explanations and map on to regional differences. ${ }^{1}$ This early attention to spatial factors in racial inequalities later carried over to the role of urban neighborhoods and schools in the lives of minority youth. Rankin's collaboration with William Julius Wilson helped extend the idea of a spatial mismatch between employment opportunities and the residential patterns for US

Koç University, Department of Sociology, Rumelifeneri Yolu 34450, İstanbul, Turkey; muergin@ku.edu.tr. 1 See, e.g., Bruce Rankin and William Falk. "Race, Region, and Earnings: Blacks and Whites in the South." Rural Sociology 56, no. 2 (1991): 224-37. 
inner-city minorities, namely the destructive consequences of minorities' physical distance to jobs. One of the important controversies of the period revolved around the concepts of the "underclass" and the "ghetto," which led scholars to examine the relationships between race, class, and residential segregation. Rankin contributed to the debate in several publications that analyzed the roles of social isolation, poverty, and residential segregation in the life chances of African American youth. ${ }^{2}$ In Good Kids from Bad Neighborhoods, a book Rankin co-authored, we find a sophisticated exploration of multiple factors, such as the individual, neighborhood, work, and school, in an attempt to counter dominant racial stereotypes and show how children growing up in disadvantaged neighborhoods are not necessarily condemned to failure and poverty. ${ }^{3}$

Bruce Rankin's work in Istanbul extended his focus on inequalities to education, economic crises, and culture in the context of contemporary Turkey. Rankin's work on education paid particular attention to gender barriers and regional disparities, examining and critiquing the role of patriarchal beliefs and practices. ${ }^{4}$ New Perspectives on Turkey was home to two of Rankin's articles that proved groundbreaking in the empirical analysis of the 2001 economic crisis. They convincingly established that the effects of economic crises amplify existing patterns of inequalities along the lines of education, age, ethnicity, and occupation. His work also showed the disproportionately devastating impact of crises on disadvantaged groups in terms of emotional and physical wellbeing. ${ }^{5}$ After 2014, Rankin embarked upon an investigation of the role of cultural boundaries in the reproduction of systems of inequality, which proved especially valuable to identifying distinct cultural groups and understanding their links with social classes. ${ }^{6}$

2 Bruce Rankin and James Quane. "Neighborhood Poverty and the Social Isolation of Inner-city African American Families." Social Forces 79, no. 1 (2000): 139-64; Bruce Rankin and James Quane. "Social Contexts and Urban Adolescent Outcomes: The Interrelated Effects of Neighborhoods, Families, and Peers on African-American Youth." Social Problems 49, no. 1 (2002): 79-100.

3 Delbert Elliott, Scott Menard, Bruce Rankin, Amanda Elliott, David Huizinga, and William J. Wilson. Good Kids from Bad Neighborhoods. (Cambridge: Cambridge University Press, 2006).

4 See, e.g., Bruce Rankin and Işık Aytaç. "Gender Inequality in Schooling: The Case of Turkey." Sociology of Education 79, no. 1 (2006): 25-43; Bruce Rankin and Işık Aytaç. "Religiosity, the Headscarf, and Education in Turkey: An Analysis of 1988 Data and Current Implication." British Journal of the Sociology of Education 29, no. 3 (2008): 273-87.

5 Bruce Rankin. "Economic Crisis and the Social Structuring of Economic Hardship: The Impact of the 2001 Turkish Crisis in Comparative Perspective." New Perspectives on Turkey 44 (2011): 11-40; Işık Aytaç and Bruce Rankin. "Unemployment, Economic Strain and Family Distress: The Impact of the 2001 Economic Crisis." New Perspectives on Turkey 38 (2008): 181-203.

6 Bruce Rankin, Murat Ergin, and Fatoş Gökşen. "A Cultural Map of Turkey." Cultural Sociology 8, no. 2 (2014): 159-79; Bruce Rankin and Murat Ergin. "Cultural Omnivorousness in Turkey." Current Sociology 65, no. 7 (2016): 1070-92. 
With his signature ironic look at life and its complexities, Bruce Rankin would have been the first to question the premise of an obituary for him and acknowledge the futility of this endeavor. His critical eye would have been quick to point out that obituaries impose an undue order to the otherwise chaotic fluctuations of life stories; that they give a positive spin on the past with their emphasis on accomplishments and completions, rather than cracks and fragments; and that they force a pernicious hierarchy on life itself by distinguishing "a publicly grievable life" from the deaths of less fortunate others. Life is too complex to summarize in a short narrative, too uncertain with multitudes of achievements and disappointments, and too valuable to taxonomize into the memorable and the forgettable. However, none of these should overshadow the significance of remembering as an act of reconnecting. Those who knew him will remember Bruce Rankin as a great inspiration with a strong work ethic, critical intellect, and exemplary career. Obituaries symbolize closure - an emphatic end, a full stop - to the story of a life. But, with his legacy in the annals of academia and in the memories of students, colleagues, and loved ones, one hopes that this obituary will instead be a testament to our continuing bonds.

7 Judith Butler. Precarious Life: The Powers of Mourning and Violence. (New York: Verso, 2003), 34. 